\title{
Supervisão de ensino: dos mitos às perspectivas emancipatórias
}

Rosângela Aparecida Ferini

Supervisora de Ensino da Secretaria da Educação do Estado de São Paulo

Doutoranda em Educação pela UNICAMP

\section{Resumo}

O artigo defende a hipótese de que a atual supervisão de ensino do sistema público estadual paulista apresenta, contraditoriamente, uma cultura de administração centrada em práticas autoritárias, fiscalizadoras e reprodutoras de políticas públicas emanadas dos órgãos centrais hegemônicos e ao mesmo tempo, implementa no seu nível de atuação, ações diferenciadas e críticas, comprometidas com a emancipação social dos agentes envolvidos. Como forma de ruptura e superação do atual paradigma de administração educacional e, em consequência de ação supervisora, apresenta novas diretrizes éticas.

Palavras-chave: Emancipação; Administração Educacional; Supervisão de Ensino.

\begin{abstract}
This work supports the hypothesis that, the actual educational supervision of the public educational policies in the Stat of São Paulo shows the contradiction of the administration culture based on authoritarian, examined and reproductive practices of the public policy derived from central bodies, and, at the same time, improves, in its acting level, special and critical actions, committed to the social emancipation of the involved agents. As a way of rupture and overcoming of the present paradigmatic of the educational administration and management, and as a result of the educational supervision, one suggests requirements to build new ethical rules to the educational supervision. In short, this work shows the educational supervision of the historical myths and their contraction with the possible identity for emancipation.
\end{abstract}

Keywords :: Emancipation; Educational Administracion; Educational Supervision. 


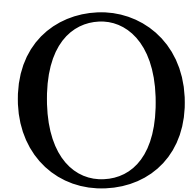

presente artigo aborda algumas considerações a respeito da atual supervisão de ensino do sistema público estadual paulista, a partir de dados de pesquisa realizada no curso de mestrado da FE/Unicamp.

Inicialmente, apresentamos um breve relato da investigação, cujo objeto de estudo versou em torno das políticas públicas de administração educacional, e, em especial, as relacionadas à supervisão de ensino pública estadual paulista.

O relato resgata as motivações, dificuldades bem como formas de análises, interpretação e compreensão da realidade pesquisada com vistas à emancipação social.

Arroyo (1985, p. 128), deixa claro

que um supervisor interessado em realizar um processo educativo de supervisão, só o conseguirá na medida em que se abra para a realidade onde está e consiga na leitura crítica dessa realidade, encontrar os pontos de referência, em nível dos conteúdos e métodos, que deverão direcionar sua ação.

As primeiras inquietações surgiram com a observação empírica da rotina e práticas de trabalho da supervisão, principalmente, a partir do final dos anos de 1990, com a presença de políticas públicas emanadas dos órgãos centrais e reproduzidas nas Diretorias de Ensino ${ }^{1}$ e Escolas, cada vez de forma mais alienantes pelos supervisores, caracterizados institucionalmente como Agentes de Estado.

Desta situação estruturou-se o problema a ser investigado: há possibilidades de superação da cultura de administração burocrática e autoritária, explicita e implicitamente praticada nas Diretorias de Ensino Paulistas, pelos supervisores de ensino, considerando suas características institucionais, mitos tipológicos e perspectivas emancipatórias?

O cotidiano revelava contradições. As práticas reprodutoras, alienadas, resignadas a uma ordem do poder governamental e de uma classe

\footnotetext{
${ }^{1}$ A Diretoria de Ensino é um órgão intermediário entre as escolas e a estrutura central da Secretaria de Estado da Educação de São Paulo.
} 
dominante conviviam com outra perspectiva, ações de resistência, críticas, dialógicas, transformadoras, que surgiam na tentativa de subverter a ordem estabelecida e de formar outros agentes, conscientes de suas possibilidades como sujeitos históricos.

A epistemologia dialética apresentou-se como Teoria do Conhecimento, que veio ao encontro dos interesses e motivações da pesquisa. Segundo Sánchez Gamboa (1998, p.18):

A epistemologia dialética como Teoria do Conhecimento se desenvolve na relação crítico-operativa entre Filosofia e Ciência, não se fecha no campo da Ciência tal como ocorre no positivismo. Torna-se Crítica do Conhecimento na medida em que utiliza as leis e categorias da dialética materialistas como instrumental crítico-reflexivo, para estudar os processos da produção científica, entendidos como processos de conhecimento humano. (...) Daí porque a reflexão sobre a ciência e a análise de seus aspectos internos (lógicos, gnosiológicos e metodológicos) e externos (histórico-sociais) são uma necessidade premente da época.

Neste contexto o método dialético norteou o percurso da pesquisa educacional e de acordo com Sanfelice (2005, p. 92), esclarecemos que dialética, neste trabalho

parte da aceitação de que as partes da totalidade educacional são, nas partes e no todo, dialéticas: a quantidade que se transforma em qualidade e vice-versa; os contrários que se interpenetram e a negação da negação (superação). Isso implica, inclusive, não excluir a lógica formal, mas afirmá-la como o contrário a ser superado.

Assim sendo, as duas categorias básicas de análise foram:

- Contradição: “o objeto é tomado como totalidade e como unidade de contrários. Torna-se um desafio captar o conflito, o movimento, a tendência predominante de sua transformação” (Sanfelice, p. 84-85).

- Movimento: "relação da parte (o objeto em estudo) com o todo, não um todo infinito para o pesquisador, mas um todo, tomado tanto quanto necessário para o melhor conhecimento do objeto” (Sanfelice, 2005, p. 85). 
Como recurso metodológico para geração de dados, elegemos o grupo focal $^{2}$. Para Gatti (2005, p. 11)

o trabalho com grupos focais permite compreender processos de construção da realidade por determinados grupos sociais, compreender práticas cotidianas, ações e reações a fatos e eventos, comportamentos e atitudes, constituindo-se uma técnica importante para conhecimento das representações, percepções, crenças, hábitos, valores, restrições, preconceitos, linguagens e simbologias prevalentes no trato de uma dada questão por pessoas que partilham alguns traços em comum, relevantes para o estudo do problema visado.

O grupo focal busca, a partir da avaliação e depoimentos realizados pelos participantes, problematizar a técnica, com base em pressupostos científicos, situando-a no contexto da pesquisa, na qual se realiza. Com relação ao tratamento do material gerado no grupo focal, esclarecemos que foram utilizados os aportes de Bardin (2004).

A partir da hipótese de que a atual supervisão de ensino do sistema público estadual paulista apresenta, contraditoriamente, uma cultura de administração centrada em práticas autoritárias, fiscalizadoras e reprodutoras de políticas públicas emanadas dos órgãos centrais, e ao mesmo tempo implementa no seu nível de atuação, ações diferenciadas e críticas, comprometidas com a emancipação social dos agentes envolvidos, buscou-se identificar, experiências e indícios de ações voltadas para a superação do autoritarismo e para a promoção de uma educação emancipatória.

As relações de poder, num ambiente complexo como o educacional, em seus diferentes níveis de organização, retratam as tensões da sociedade de classes no capitalismo. Neste sistema de relações o Estado possui uma função ideológica ao implementar as políticas de administração educacional, pensadas no nível macro e implementadas no micro. Porém, estas só cumprem sua função quando incorporadas pelos diferentes agentes do sistema. Estas relações interpessoais no nível micro é que acabam por

2 Os referencias a respeito de grupo focal podem ser encontrados nas obras de Wagner (1999); González Rey( 2002); Gatti (2005) entre outros. 
determinar modelos ou formas de administrar que condicionam as ações dos demais envolvidos na administração local, controlando e delimitando os discursos, e consequentemente, as práticas.

Para Foucault (1971, p.11)

a produção do discurso é ao mesmo tempo controlada, selecionada, organizada e redistribuída por um certo número de procedimentos que têm por papel conjurar dele os poderes e perigos, de dirigir o acontecimento aleatório, de afastar dele a pesada, a irredutível materialidade. ${ }^{3}$

Diante destas exposições iniciais e para melhor apreender o objeto de estudo em seu movimento e de forma objetiva, realizamos uma pesquisa histórica para identificar as matrizes e estigmas culturais e administrativos da organização social e institucional da educação, escola e política no Brasil, bem como, os modelos de administração e a respectiva correspondência político-social em que se assentam essas matrizes. Os autores de referência para este estudo foram Nagle (1976), Gadotti (1996), Nosella (1998), Coraggio (2000), Saviani (2002), Aggio (2003), Heloani (2003), Nunes (2005), Lombardi (2005), Chauí (2006).

Com relação às matrizes culturais estabelecemos três períodos, que se constituíram em marcos ideológicos para a administração pública educacional, influenciando de forma direta as atuais características institucionais, mitos tipológicos e identidade da supervisão de ensino paulista.

O primeiro período é marcado pelas reformas educacionais Francisco Campos e Gustavo Capanema, iniciadas a partir da década de 1930, na denominada Era Vargas do governo. O cunho autoritário, populista e fascista são as principais características percebidas na administração do governo à época. O inspetor escolar, profissional que exercia as funções de supervisão de sistema a época, era caracterizado como fiscalizador.

${ }^{3}$ FOUCAULT, M. L'ordre du discours. Paris: Gallimard, 1971. Apud: BRANDÃO, Helena H. Nagamine. Introdução à análise do discurso. $-2^{\mathrm{a}}$ ed. - Campinas, SP: Editora da UNICAMP, 2004. (p. 99). 
A proposta modernizadora tecnicista autoritária, retratada na Lei Federal 5692/71, representa o segundo marco. Esse período caracteriza-se pelas influências externas, dos acordos MEC-USAID, onde os princípios de organização do trabalho, pautados pela sua divisão, saem das fábricas e atingem de maneira mais acentuada a educação e as escolas.

As Teorias de Administração de Empresas são praticamente transpostas para o universo escolar, a seguir o princípio da 'mercadorização' imposta pelo capitalismo e da submissão do país aos interesses econômicos norte-americanos. O técnico-burocrata representa a referência profissional deste período.

A LDB 9394/96, nascida do triunfo conjuntural do neoliberalismo, constitui-se em terceiro marco. As premissas do neoliberalismo chegam à administração pública educacional através do discurso da necessidade de reformas para uma maior racionalização da máquina burocrática e da implementação de programas voltados para a gestão como forma de resolver os problemas da educação e de sua administração.

Na atualidade, além da técnica, acrescenta-se a competência, ambas relacionadas à competitividade e ao individualismo na era da globalização.

Esses três marcos ideológicos constituem-se sob a égide de um modelo de administração conservador, autoritário e regulador, que apresenta matrizes culturais determinantes nas características institucionais, mitos tipológicos e identidade da supervisão.

A partir desses referenciais históricos pudemos situar e compreender a supervisão de ensino das características institucionais históricas aos mitos tipológicos vigentes em constante processo de tensão.

A origem das atribuições e competências da supervisão de ensino e do supervisor de ensino apresenta-se na legislação federal do início da República e em outros dispositivos do Estado de São Paulo, editados posteriormente, que de forma complexa e dialética, conduziram as atuais características institucionais e a construção dos mitos tipológicos. 
Nos dispositivos legais ${ }^{4}$ que regem a constituição da ação supervisora, dois eixos foram percebidos ao longo da análise. O primeiro diz respeito à relação inspeção-supervisão, sob a ótica do “controle” determinado pelo Estado, exercido na antiga inspeção escolar, que gerou os primeiros mitos desta profissão.

O segundo encontrou no momento de transformação da nomenclatura inspeção para supervisão, a influência norte-americana para a construção do mito da "reprodução", por meio de modelos prontos difundidos por ideólogos do governo e organismos internacionais.

Os mitos iniciais de controle e reprodução entram em choque com a função essencial, atualmente defendida para a supervisão - a política. Na constituição da profissionalidade, percebemos que a natureza política da supervisão, transforma-se culturalmente, também em mito, necessitando ser desvelada para produzir novas reflexões críticas e práticas emancipatórias por seus agentes.

O impacto das políticas públicas, principalmente a partir do final dos anos de 1990, desestruturou este profissional, conforme pudemos verificar nos dados gerados no grupo focal, realizado com supervisores da rede pública estadual paulista.

A constante mudança de programas de governo gerou rupturas na organização e produção do trabalho. A perspectiva de processo, de uma visão global se perde. A fragmentação reduz o fazer e o sentido da ação parece desaparecer num começo sem fim, na eterna cultura do recomeçar a cada novo governo.

\footnotetext{
${ }^{4}$ Os principais dispositivos legais investigados foram: Lei Federal $n^{\circ}$ 88, de 08/09/1892; Lei/SP ñ 520, de 26/08/1897; Leis Orgânicas de 1946 (Reforma Francisco Campos e Gustavo Capanema); Circulares das Diretorias de Ensino (órgãos subordinados ao Ministério de Educação e Saúde) - Circular no 1, de 15/03/1951 - Curso Secundário; LDB $n^{\circ}$ 4024/1961; Decreto/SP no 39.380 - DOE 23/11/1961; Lei Federal ${ }^{\circ}$ 5540/1968; Parecer/CFE $n^{\circ}$ 252/1969; Lei Federal 5692/1971; LC/SP 114/1974; Decreto/SP $n^{\circ}$ 5586/1975; LC/SP n 201/1978; Decreto SP/ no 16.995/1981; Decreto/SP no 17.329/1981; Decreto/SP no 18.412/1982; LC/SP 444/1985; LC/SP n 744 /1993; Resolução SE/SP no 192/1995; LDB 9394/1996; LC/SP 836/1997; Parecer CEE/SP nº 67/1998; Comunicado SEE/SP de 30/07/2002; entre outros.
} 
A perspectiva de extinção do supervisor de ensino, como profissional da carreira do magistério, está sempre presente, talvez imposta pela divindade grega Cronos (Tempo), que devorou a própria prole. Aquele que traz o fim a todas as coisas que começam.

Contraditoriamente, os primeiros inspetores e supervisores, passaram do mito de Minerva, a deusa da sabedoria, à condição de estátuas petrificadas pelo olhar de Medusa.

Essas transformações aconteceram gradativamente, ao longo das mudanças de governo, das formas de administrar e implementar as políticas públicas, sob a influência dos marcos ideológicos e que acabaram por gerar uma crise de identidade.

Aos supervisores que esperavam encontrar o Olimpo, retratado na Odisseia de Homero, restou apenas à busca do paraíso perdido.

O contexto e complexidade das regulamentações legais para o desenvolvimento da ação supervisora criou o perfil e o supervisor ideal. As políticas neoliberais cumpriram o último trabalho de Hércules: trouxe do mundo de Hades a terra, Cérbero, após subjugá-lo.

O supervisor ideal transforma-se em monstro, sem identidade: cada cabeça vê uma realidade. Considerado monstro causa medo em todos a sua volta. Até aos que só o conhecem de “ouvir falar”. Apesar da truculência metafórica ela nada perde a realidade.

O supervisor ideal, criação de um perfil ideal, apresenta a reunião de um conjunto de características institucionais (atribuições e competências legais) dos deuses do Olimpo, todavia, mitologicamente reunidas em um só deus, que sabemos não pertencer a este mundo. Diante da inexistência do Supervisor ideal, resta-nos um Cérbero que, subjugado, torna-se monstro de si próprio: vê várias faces sem saber qual a sua; vê dois mundos sem saber ao qual pertence; mito e realidade confundem-se.

Mas, a realidade não ocupa os extremos desses mundos opostos. Ela ocupa este mundo em que vivemos, com todas as suas contradições. É na 
recusa da simples facticidade, que surge o olhar dialético, de negação da própria negação, percebendo os limites, mas com vistas à superação e novas possibilidades.

Neste processo, após recuperar características institucionais e mitos tipológicos que permearam a construção histórica dos supervisores de ensino a fim de analisarmos as perspectivas emancipatórias na prática destes profissionais nos deparamos com indícios de uma crise de identidade.

A pesquisa aponta quatro fatores determinantes desta crise de identidade:

1) o primeiro encontra-se na própria estrutura e organização das características legais da supervisão de ensino, que são descritas por um arcabouço extremamente vasto, especificando em minúcias as ações que deveriam ser desenvolvidas pelos supervisores. Estas geram um “emaranhado legal”, complexo, impraticável na totalidade das ações cotidianas dos supervisores em face de questões estruturais;

2) desconhecimento da trajetória histórica da supervisão e sua interface com as políticas públicas, com seus marcos e mitos fundadores, de acordo com as categorias explicitadas neste trabalho (características institucionais, mitos tipológicos, identidade, relações de poder, perspectivas emancipatórias). O desconhecimento da história gera alienação e restrições à compreensão crítica da realidade;

3) o terceiro fator está intimamente ligado ao segundo, ou seja, às origens históricas da supervisão. Mas fizemos um destaque aparte pela relevância e atualidade da discussão. Esse fator refere-se à matriz cultural dualista, administrativo versus pedagógico, que se constituiu a partir do momento de ruptura na profissão com a passagem da inspeção para a supervisão pedagógica. A mudança ocorreu apenas em termos de denominação. A presença do dualismo que separa administrativo e pedagógico habita o imaginário dos atuais supervisores de ensino, norteando as escolhas e prioridades na atuação; 
4) por fim, o quarto fator determinante da crise de identidade surge justamente da diversidade de mitos tipológicos existentes (o supervisor fiscalizador; o técnico-burocrata; o tarefeiro; o alienado; o supervidão; entre tantos outros). A fragilidade das características institucionais e de referenciais teóricos próprios favorece a cooptação de seus quadros em momentos de conflitos.

Há que se esclarecer que os fatores acima apontados se articulam em diferentes combinações dialeticamente e, somente para efeitos de exposição, aparecem especificados em separado.

Os fatores apontados como determinantes da crise de identidade são ainda, permeados pelas relações de poder, como sempre veladas, podendo ser apreendidas sutilmente em discursos diversos dos supervisores. Apesar de uma centralidade da SEE, na condução das políticas das diretorias, as formas como estas acontecem no locus da DE dependem do tipo de administração implementada pelos Dirigentes.

A crise de identidade, revelada por meio dos depoimentos gerados no grupo focal e do aporte teórico deste trabalho, pode ser representada pela figura mitológica da esfinge: decifra-me ou te devoro. Atualmente a identidade da supervisão é multifacetada e difusa, pois, ela está muito mais relacionada às práticas individuais “deste ou daquele” supervisor, não sinalizando para uma identidade construída coletivamente.

As visões de mundo dos supervisores, por vezes, antagônicas e pautadas na lógica do capital, apresentam-se como dificultadores para a superação dessa realidade.

Assim sendo, a supervisão de ensino paulista encontra-se diante de sua própria esfinge que, se não for decifrada coletivamente, acabará devorada pelo sistema imposto pelas políticas públicas educacionais.

Mas, apesar da situação exposta nas teses preliminares, encontramos também na realidade as possibilidades de superação de práticas autoritárias na administração da DE, e, em especial as do grupo de supervisores do 
sistema público estadual de ensino paulista. Mesmo diante das contradições estes profissionais sinalizam necessidades de rupturas, de novas construções e principalmente, a necessidade de uma ação supervisora coletiva pautada por princípios comuns na busca de uma educação de qualidade para todos.

Diante dos mitos tipológicos, marcos ideológicos e suas respectivas matrizes culturais, centrados no autoritarismo, presentes há séculos em nossa história, a transgressão e utopias movem os agentes comprometidos, politicamente, com a emancipação.

Reafirmar as ações que incorporam a práxis do Supervisor Emancipador se faz necessário. Este representa o profissional consciente de sua função social, que vive as contradições de seu tempo, entretanto, tendo a percepção dessas por meio de estudos críticos, processos de formação continuada, discussões coletivas, entre outros, posiciona-se de forma "política” a favor de uma educação emancipadora, buscando desvelar e romper com os mitos e, nesta forma de atuar, constrói ativamente, como sujeito histórico, uma identidade coletiva de supervisão, emancipadora em sua essência, com novas diretrizes éticas para o perfil da ação supervisora emancipatória.

Como indicadores para essas diretrizes éticas, apontamos entre outros, a necessidade dos agentes apresentarem: disposição política para a ação supervisora; capacidade de organização; capacidade de resolver conflitos; sensibilidade social para com as situações que geram exclusões; capacidade argumentativa; respeito às decisões coletivas; capacidade de trabalho em grupo; conhecimentos-técnicos para a atuação, entre outras.

Para a construção desse novo senso comum cabe a cada supervisor de ensino, assumir-se como intelectual orgânico, ideologicamente comprometido com a sua formação e com a de sua classe. Neste processo será necessário romper com as reduções cognitivo-instrumentais impostas pelo mundo dos sistemas e estabelecer no seu cotidiano amplas situações de comunicação, de conversação, resgatando a simplicidade e sinceridade das relações com todos os envolvidos ao seu redor. 
Por isso, compreender a supervisão de ensino, dos mitos à sua identidade, é uma condição sine-qua-non para que os supervisores avancem em suas constatações e comecem a indignar-se. Indignar-se com a reprodução de uma ordem vigente; indignar-se com o nível de exclusão e miséria social; indignar-se com o despreparo ou desconhecimento da profissão pelos próprios supervisores de ensino, que gerou a crise de identidade, resultado de políticas públicas e não do potencial humano destes profissionais; enfim indignar-se com a consciência ingênua inconcebível a um profissional que tem por essência a função de hominizar e humanizar, participando de um processo de construção de homens e mulheres emancipados, capazes de realizarem-se no mundo em que vivem, de forma material e objetiva e não simplesmente no plano metafísico ou das ideias.

Esperamos que as considerações apresentadas neste artigo possam inquietar os supervisores dos diferentes sistemas de ensino, pesquisadores, profissionais da educação e também outros interessados na busca de uma práxis educacional que a cada dia mais se aproxime do compromisso com a emancipação social.

\section{Referências Bibliográficas}

AGGIO, Alberto (2003). "A emergência de massas na política latino-americana e a teoria do populismo". In: AGGIO, Alberto; LAHUERTA, Milton (Orgs). Pensar o século XX: problemas políticos e bistória nacional na América Latina. São Paulo: Ed. UNESP, p. 137-164.

ARROYO, Miguel G (1985). "Subsídios para a práxis educativa na supervisão educacional". In: BRANDÃO, Carlos Rodrigues; et. al.. Educador Vida e Morte. 6. ed. Rio de Janeiro: Graal Editora, p.105-133.

BARDIN, L. Análise de Conteúdo. 4. ed. Lisboa/Portugal: Edições 70, 2004.

BUENO, Maria Sylvia Simões (2003). "Revisitar a minha ação supervisora: estratégia para explicitar e discutir caminhos e perspectivas da supervisão de ensino, em território paulista, na virada do milênio". In: MACHADO, Lourdes Marcelino; MAIA, Graziela Zambão Abdian (Orgs.). Administração e Supervisão escolar: questões para o novo milênio. São Paulo: Pioneira Thomson Learning, p. 2548. 
CHAUÍ, Marilena (2006a). Cultura e Democracia: o discurso competente e outras falas. 11. ed. São Paulo: Cortez Editora.

(2006 b). Brasil: mito fundador e sociedade autoritária. São Paulo: Editora Fundação Perseu Abramo. 6. reimpressão. (Coleção Histórias do povo brasileiro).

CORAGGIO, Luis José (2000). "Propostas do Banco Mundial para a educação: sentido oculto ou problemas de concepção?” IN: TOMMASI, Lívia De, WARDE, Mirian Jorge, HADDAD, Sérgio. (orgs.). O Banco Mundial e as Políticas Educacionais. 3. ed. São Paulo: Cortez, p. 75-124.

FERINI, Rosângela Ap. Supervisão de Ensino: características institucionais, mitos tipológicos e perspectivas emancipatórias. Dissertação de mestrado. FE/Unicamp. Campinas, 2008.

FERREIRA, Naura Syria carapeto (2002). "Supervisão educacional no Brasil: trajetória de compromissos no domínio das políticas públicas e da administração da educação". In: FERREIRA, Naura Syria carapeto (Org.). Supervisão Educacional para uma escola de qualidade. 3 ed. São Paulo: Cortez Editora, p. 235-254.

FOUCAULT, Michel. $A$ ordem do discurso. 12. ed. [Tradução de Laura Fraga de Almeida Sampaio]. São Paulo: Edições Loyola, 1996 (1970).

GADOTTI, Moacir (1996). A Formação do Administrador da Educação: Análises de Propostas. Revista Brasileira de Administração da Educação. Porto Alegre, RBAE v. 2, n. 12, jul./dez., ANPAE.

GODOY, Lucia Helena Franco de Godoy (2005). As representações Sociais dos Supervisores Escolares da Rede Municipal de São Paulo. 144 f. Mestrado em Psicologia da Educação - Pontifica Universidade Católica de São Paulo, São Paulo. (mimeo)

GATTI, Bernardete Angelina (2005). Grupo focal na pesquisa em ciências sociais e bumanas. Brasília: Líber Livro Editora.

GONZÁLEZ REY, F. L. (2002). Pesquisa qualitativa em psicología - caminhos e desafios. São Paulo: Pioneira-Thomson Learning.

HELOANI, Roberto (2003). Gestão e organização no capitalismo globalizado: história da manipulação psicológica no mundo do trabalbo. São Paulo: Atlas.

LOMBARDI, José Claudinei (2005). "A Importância da Abordagem Histórica da Gestão Educacional”. In: Estudo, Pensamento e Criação. Livro 2., v. 3. Campinas, SP: Graf. FE, p.181-188. 
MACHADO, Lourdes Marcelino; MAIA, Graziela Zambão Abdian (Orgs.) (2003). Administração e Supervisão Escolar: questões para o novo milênio. São Paulo: Pioneira Thomson Learning.

NAGLE, Jorge (1976). Educação e Sociedade na Primeira República. São Paulo: EPU; Rio de Janeiro, Fundação Nacional de Material Escolar.

NOSELLA, Paolo (1998). "A escola brasileira no final de século: um balanço". In: FRIGOTTO, Gaudêncio (Org.). Educação e crise do trabalho: perspectivas de final de século. Petrópolis, RJ: Vozes, p. 166-188. (Coleção estudos Culturais em Educação).

NUNES, César (2005 a). Políticas Públicas Educacionais. Jornal APASE. São Paulo, ano VI, n. 15, (Suplemento Pedagógico APASE).

(2005 b). Economia, Educação e Sociedade: Matrizes Politicas e Estigmas Culturais da Administração Escolar no Brasil. Campinas, SP. (Gestão Educacional - Gestão Escolar: Abordagem Histórica- FE/UNICAMP) mimeo.

QUAGLIO, Paschoal (2003). “Administração, Supervisão, Organização e Funcionamento da Educação Brasileira". In: MACHADO, Lourdes Marcelino; MAIA, Graziela Zambão Abdian (Orgs.). Administração e Supervisão escolar: questões para o novo milênio. São Paulo: Pioneira Thomson Learning, p. 49-58.

RAPHAEL. Hélia Sônia (2003). "A ação supervisora e a construção do projeto de avaliação escolar". In: MACHADO, Lourdes Marcelino \& MAIA, Graziela Zambão Abdian (orgs.). Administração e Supervisão escolar: questões para 0 novo milênio. São Paulo: Pioneira Thomson Learning.

SÁNCHEZ GAMBOA, Silvio (1998). Epistemologia da Pesquisa em Educação. Campinas, Práxis, 2. reimpressão.

SANFELICE, José Luís (2005). "Dialética e Pesquisa em Educação". In: LOMBARDI, José Claudinei; SAVIANI, Dermeval (Orgs.). Marxismo e Educação: debates contemporâneos. Campinas, SP: Autores Associados: HISTEDBR, p. 69-94.

SAVIANI, Dermeval (1985). Educação: do Senso Comum à Consciência Filosófica. São Paulo: Cortez Editora: Autores Associados.

(2002). A supervisão educacional em perspectiva histórica: da função à profissão pela mediação da idéia. In: FERREIRA, Naura Syria carapeto (Org.). Supervisão Educacional para uma escola de qualidade. 3 ed. São Paulo: Cortez Editora, p. 13-38.

SILVA, Igínia Caetana Finelli (2003). A (Re)Invenção da Municipaliz̧ação do Ensino: o avesso e o direito na representação social dos responsáveis pela gestão do ensino fundamental público no município. f. 239.Doutorado em Educação. FE/UNICAMP, Campinas. 
SILVA JÚNIOR, Celestino Alves da (2002). "O espaço da administração no tempo da gestão". In: MACHADO, Lourdes Marcelino; FERREIRA, Naura Syria Carapeto (Orgs.). Política e Gestão da Educação: Dois Olhares. Rio de Janeiro: DP\&A, p. 199-211.

(1984). Supervisão da Educação: do autoritarismo ingênuo à vontade coletiva. São Paulo: Edições Loyola.

TACHINARDI, Vera Lúcia (2004). O Supervisor de Ensino Paulista: Da Proletarização às Perspectivas de Desenvolvimento Profissional. Mestrado em Educação - Universidade de São Paulo (USP), São Paulo. (mimeo).

WAGNER, W. Descrição, explicação e método na pesquisa das representações sociais. In: GUARESCHI P.; CHELOVITCHI S. Jovi (Orgs.). Textos em representações sociais. 5 ed. Petrópolis:Vozes, 1999. p.149-186. 